\title{
Gaza Everywhere: exploring the applicability of a rhetorical lens in $\mathrm{HCl}$
}

\author{
Omar Sosa-Tzec \\ Indiana University \\ 901 E. $10^{\text {th }}$ Street \\ Bloomington, IN 47408 \\ omarsosa@indiana.edu
}

\author{
Erik Stolterman \\ Indiana University \\ 901 E. $10^{\text {th }}$ Street \\ Bloomington, IN 47408 \\ estolter@indiana.edu
}

\author{
Martin A. Siegel \\ Indiana University \\ 901 E. $10^{\text {th }}$ Street \\ Bloomington, IN 47408 \\ msiegel@indiana.edu
}

\begin{abstract}
By examining application software as a type of rhetorical artifact, it is possible to highlight its social, ethical and moral implications. In this paper, we explore one possibility for such a lens: application software functioning as a visual enthymeme. To explore the applicability of that concept in HCI, we analyze one web application as a first step. In our analysis, we observe that interaction and usability are two features that support an application in functioning as a visual enthymeme. Also, online sharing could help the user take the role of the arguer. Our analysis allows us to outline the elements of a user-centric persuasive experience and shows promise for further explorations regarding the applicability of rhetoric in HCI.
\end{abstract}

\section{Author Keywords}

Visual Enthymeme; Rhetoric; Persuasive Technology; Experience Design; Design Theory

\section{ACM Classification Keywords}

H.5.m. Information interfaces and presentation (e.g., HCI): User Interfaces - Graphical User Interfaces (GUI), Screen Design, Theory and Methods

\section{INTRODUCTION}

Rhetoric is a critical human ability that permeates all forms of human communication [7,10]. Rhetoric can mobilize people; it can influence their perception of reality and truth [7]. Many people are exposed to symbolic, persuasive, and visual artifacts every day $[8,12,13]$. Some of these artifacts are intended to make a point, increasing awareness about a particular situation, and thus change the beliefs, attitudes or values of people. For example, the 1996 advertisement of United Colors of Benetton showed three hearts, labeled "White, Black, Yellow," intended to point out that people are equal regardless of their skin color. ${ }^{1}$ This is an example of a visual enthymeme, a form of argument aimed at persuading an audience, rather than finding truth. These visual enthymemes can be found in printed advertisements, televised political campaigns, and documentary photographs.

Copyright $\subset 2015$ is held by the author(s). Publication rights licensed to Aarhus University and ACM

5th Decennial Aarhus Conference on Critical Alternatives

August 17 -21, 2015, Aarhus Denmark

DOI: http://dx.doi.org/10.7146/aahcc.v1i1.21314
An enthymeme is an argument that provides the claim or conclusion to the audience, but leaves one premise unstated, thus it is also known as a truncated syllogism. It then becomes the task of the audience to fill in that premise $[7,13]$. In the case of a visual enthymeme, the observer detects or interprets a claim or conclusion from the observation of the composition, whose elements serve as the stated premise, and fills in the unstated premise through reasoning derived from such observation [13].

In this paper we argue that rhetoric is an appropriate and useful lens in HCI. To explore the applicability of this lens, we focused on one possibility: application software functioning as a visual enthymeme. In particular, we focus on applications with a GUI. As a first step of this exploration, we chose to analyze a web application known as "Gaza Everywhere" which compares the Strip of Gaza with other territories in the world [16]. During news coverage regarding the Gaza Strip in the summer of 2014, relevant tweets, and an online publication from The Independent [3] suggested that Gaza Everywhere could function as a visual enthymeme. The application's interface contains demographic statistics about the Gaza Strip. It also contains a Google Maps widget that overlaps the Gaza Strip with any territory selected by the user. Moreover, it allows the user to adjust the position and orientation of the Gaza Strip in the map. Tweets about the application are also shown in the interface. Through the analysis of the application's interface, interaction, and usage, we observe that Gaza Everywhere illustrates a case of visual enthymeme. Also, we notice that interaction and usability are two features through which the user can fill in the unstated premise. Moreover, online sharing provides a means for the user to take the role of someone making an argument.

This paper is structured as follows. First, we present our case study. Second, we discuss some observations derived from the analysis of Gaza Everywhere. Third, we emphasize possible ways in which a rhetorical lens could be advantageous in the analysis and design of software.

\section{CASE STUDY}

\section{Object of analysis}

The interface of Gaza Everywhere (GE) is mostly composed of a Google Maps widget. It also includes a Twitter widget and some demographic information about the Gaza Strip. At the beginning of the interaction, the map shows a 
translucent red shape of the Gaza Strip overlaying its territory (Fig. 1). As a result of a search, the map places the translucent shape on the territory of interest. At any time during the interaction, the user can zoom and drag the map, as well as drag and rotate the translucent shape. Also, the software allows the user to share the current state of the map online or take a screenshot of it. The user can access the source code through GitHub or embed the application in a webpage.

According to A. Nassri, author of GE, the web application is intended to "help visualize Gaza's relative size in comparison with other territories in the world." Most of the tweets shown in the interface's Twitter widget align with this description. Yet, some of them express a political opinion, including a note from i100, an online publication from The Independent [3]. In that note, images derived from the interaction with GE are used to support the note's claim, "Gaza Everywhere app highlights true scale of humanitarian crisis". The web application is embedded at the end of the note, so the user can explore the claim herself.

\section{Analysis and Observations}

The impact of GE relies on its GUI. The physicality of the interface depends on the device being used to interact with the web application (e.g., smartphone). However, the device has no major effect on the visual information or the interaction (i.e., search, interaction with the map and sharing online). GE doesn't employ audio in its composition. However, the visual information conveyed in the map is inaccurate since Google employs a variation of the Mercator projection. In this sense, the GE's intent could be regarded as illustrative, rather than affirmative. GE's intent is not oriented to provide a territorial truth.

Regardless of the stated intent of GE, each user has a different awareness regarding the conflict in the Gaza Strip, which affects the perception of the application's intent. For example, some users might see GE as a means to emphasize political issues. The note from The Independent's i100 is an exemplar of this situation. Gaza Everywhere gives room for several interpretations that are related to that awareness. The interpretations correspond to claims that can be only supported through the combination of reasons derived from the user's awareness and reasons provided through the interface's information. These characteristics allow GE to be classified as a visual enthymeme [13].

Regarding the interface, the detected or interpreted claim is supported by the overlap shown by the map in juxtaposition with the demographic information shown on the interface. Yet, such a claim is only accessible after interaction with the web application. The initial state of GE represents a visual identity wherein Gaza is equal to Gaza since the translucent shape and the territory shown on the map are the same, including their dimension and orientation. Nonetheless, the shape becomes a metaphorical visual unit of measurement after interaction with the web application. Later, the capability of manipulating the shape helps the user in-

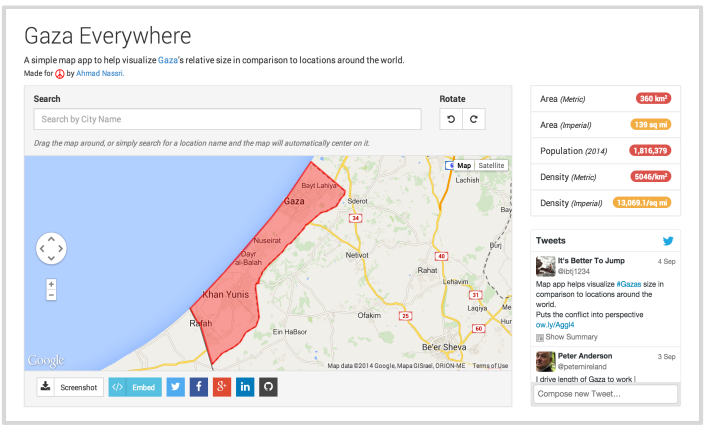

Figure 1. Initial state of GE. Screenshot from the WWW.

crease her awareness while doing visual comparisons with GE. Unlike other traditional forms of visual enthymeme, GE allows the user to play with the composition at will. That means altering the GUI as a result of interaction with the application. Traditional forms of visual enthymeme tend to be static $[12,13]$. However, the visual comparisons in GE can be done at any time and place as long as the user has access to the Internet and a device with a web browser. Those visual comparisons could elicit experiential knowledge, particularly the territories in which the user has lived. In that regard, GE could elicit sensations and emotions as a consequence of interaction, supporting not only the user experience but also the detected or interpreted claim. Thus, interaction and experiential knowledge help the user to fill in the unstated premise in order to support the detected or interpreted claim. Nevertheless, the user's awareness is affected after each interaction and by other sources of information. Consequently, the user might revisit the detected or interpreted claim, which makes the persuasive effect of GE evolve with the user.

The user might be familiar with Google Maps, which makes the interaction with GE simple. Looking for a particular territory and adjusting the map is a task that should not represent a major usability issue. GE's usability supports filling in the unstated premise. Later, it is relatively easy for the user to share an image or link of the current map. Another user that observes that map follows the same dynamics as the first user: detect or interpret a claim and validate it based on her awareness about the Gaza Strip and the territory shown on the map. In a similar fashion, access to the source code allows a knowledgeable user to modify GE in order to reflect her vision of the web application and thus affect other users. These characteristics give GE a versatility that is not commonly seen in traditional forms of visual enthymemes.

\section{DISCUSSION}

The case of Gaza Everywhere exemplifies how application software can work as a visual enthymeme. An enthymeme, either linguistic or visual, is rooted in probability; it relies on the beliefs, presuppositions, and experiences of the audience [7]. Consequently, software functioning as a visual enthymeme not only relies on its design in order to be persuasive; it also relies on the user's beliefs, presuppositions, 


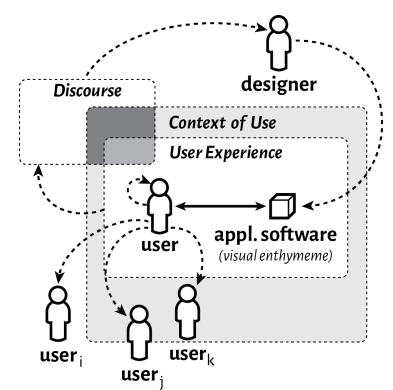

Figure 2. Elements of the user experience when interacting with software functioning as a visual enthymeme.

and experiences in order to leverage its persuasive character. In that sense, the user is placed as the central element of a persuasive experience. Based on our analysis, placing the user in that position causes the persuasive character of the application software to be conditioned by: 1) the user's computer and information literacy; 2) the user's beliefs, presuppositions, and experiences, especially those related to the situation for which the application was intended; 3) the effect of the particular characteristics found in the context of use, including the influence of the discourse [10] about the situation for which the application software was intended and the rhetorical exchange with other people (Fig. 2).

Moreover, none of these conditions are static. After each interaction with the application software, the user gains knowledge and a certain rhetorical agency to influence the discourse related to the situation for which the software was intended. That influence occurs at least at a personal level. In terms of persuasive technology, this means inheriting an autogenous persuasive intent [9]. However, GE illustrates that the technical features of an application (e.g., online sharing), as well as its usability could expand the scope of that influence. One user could persuade other users to interact with the application. In terms of persuasive technology, the user of software functioning as a visual enthymeme could become an element of the exogenous persuasive intents [9] to other potential users. Moreover, the impact of such an influence could affect the designer and hence future designs. As we learned from GE, software working as a visual enthymeme outlines a user-centric persuasive experience, a set of complex, evolving relations of people, technology, and discourse (Fig. 2).

\section{OUTLINING THE APPLICABILITY OF RHETORIC IN HCI}

Throughout this paper, we have illustrated how application software can function as a visual enthymeme. The case of $\mathrm{GE}$ is pertinent to HCI because it illustrates that design is inherently persuasive [19] and functions as an argument $[5,6]$, regardless of the designer's intent. Certainly, the case of GE provides a glimpse of the implications of application software functioning as a visual enthymeme. Yet, it doesn't completely illustrate the generative applicability of the concept. For instance, this analysis does not address the use of topoi, the lines of reasoning for inventing persuasive arguments [7], nor rhetorical figures for the composition of software functioning as a visual enthymeme. Thus, we point out the opportunity to explore the interrelation and applicability of rhetoric to the design of application software and the so-called user experience. Below, we highlight some implications of adopting a rhetorical lens in HCI and call for further research efforts in this direction.

A rhetorical lens could help analyze or generate a design of application software. Efforts related to analyzing a design would contribute to the existing body of knowledge in HCI focused on the persuasive and phenomenological aspects of technology [e.g., 2,9,19 and Fallman in 24]. Such an analysis could reveal aspects that help the designer understand the dynamics and intricacies of a persuasive user experience (e.g., Fig. 2). A rhetorical lens could aid the designer to criticize and reflect upon the design of application software, especially in the comprehension of denotations and connotations conveyed through the design, and thus the meaning that emerges during the user experience $[6,15,22]$.

Efforts related to generating a design can contribute to many aspects of HCI. Here, we will emphasize how it contributes to the existing body of knowledge in HCI focused on design pedagogy [11,23]. A rhetorical lens would allow the designer to understand the design of application software as a composition intended to address a (rhetorical) situation that needs to be solved or improved $[6,7,14,20]$. Additionally, it provides vocabulary for the designer to characterize the participants involved in the user experience and their interrelations [e.g., 1,6,18 and Christensen \& Hasle in 24]. This might support reflection-in-action [21] during the design process due to the designer's awareness of the current rhetorical situation and the people involved, as well as the possible impact of the design approach used in composing the solution [e.g., 14, 20,22].

Considering the design of application software as a composition encourages the exploration of tropes and schemes, the so-called figures of speech or rhetorical figures, as a generative tool for the designer. In graphic design, such an exploration has helped teach designers to conceptualize before execution, and to be aware about the social, moral and political dimensions of design [8]. An understanding about rhetorical figures could help the designer not only better comprehend the concept of metaphor and metonymy, probably the most used rhetorical figures in $\mathrm{HCI}$, but also to notice and conceptualize interfaces and interactions beyond these two figures.

Besides understanding the rhetoricity of $\mathrm{HCI}$, rhetorical knowledge and experience could expand the designer's set of competency [17]. The designer could apply rhetorical knowledge in order to convey a design argument before peers, the client, and other stakeholders during the design process. Consequently, the designer could strengthen her ability to reflect-on-action [21]. Rhetoric entails persuasion, either in the form of communication that brings about 
change in people [4] or in identification with common ideas, attitudes or material possessions [10]. This could help the designer achieve an empathetic state of alignment not only with the client but also with the user. Knowing about rhetoric reinforces the following goals: that the agency of all the people involved in the process should be managed, trust created, and a common understanding achieved [17].

\section{CONCLUSION}

In this paper, we took a first step exploring one way through which a rhetorical lens can be applied to the analysis of software. We analyzed Gaza Everywhere, which illustrates the possibility of application software functioning as a visual enthymeme. This analysis allowed us to outline the set of complex, evolving relations involved in such a case, introducing a schema of user-centric persuasive experience. We consider that a rhetorical lens could bring awareness of the social, moral and ethical implications not only about a design but also about the user experience. Providing such a lens to designers could help them comprehend or become sensitive to the pervasiveness of everyday rhetoric, intentional and unintentional. The user experience could be interpreted as a rhetorical interface between one person, other people, and artifacts. Through this interface discourses are shaped - discourses that go back to the designers and influence the way and with whom they identify.

\section{ACKNOWLEDGMENT}

This work is supported in part by the National Science Foundation (NSF) Grant Award no. 1115532. Opinions expressed are those of the authors and do not necessarily reflect the views of the entire research team or the NSF.

\section{REFERENCES}

1. Arvola, M. The Mediated Action Sheets: A Framework for the Fuzzy Front-End of Interaction and Service Design. Proc. European Academy of Design Conference, (2013).

2. Bardzell, J. Interaction Criticism: An introduction to the practice. Interacting with Computers 23, 6 (2011), 604621. Elsevier.

3. Barlett, E. Gaza Everywhere app highlights true scale of humanitarian crisis. i100 from The Independent (August 14, 2014). Shortened URL: http://goo.gl/b3t2lV

4. Bostrom, R.N. Persuasion. Pretince-Hall, 1983.

5. Buchanan, R. Declaration by Design: Rhetoric, Argument, and Demonstration in Design Practice. Design Issues 2,1 (1985) 4-22.

6. Carnegie, T.A.M. Interface as Exordium: The Rhetoric of Interactivity. Computers and Composition 26, 3 (2009) 164-173. Elsevier.

7. Covino, W.A., \& Jolliffe, D.A. Rhetoric: concepts, definitions, boundaries. Allyn and Bacon, 1995.

8. Ehses, H., \& Lupton, E. Rhetorical Handbook. An Illustrated Manual for Graphic Designers. Design Papers 5 (1988), 1-39.
9. Fogg, B.J. (1998). Persuasive Computers: Perspective and Research Directions. In Proc. CHI '98. ACM Press/Addison-Wesley (1998), 225-232

10. Foss, S.K., Foss, K.A., \& Trapp, R. Contemporary Perspectives on Rhetoric. $2^{\text {nd }}$ Edition. Waveland Press, 1991.

11. Getto, G., Potts, L., \& Salvo, M.J. Teaching UX: Designing Programs to Train the Next Generation of UX Experts. SIGDOC '13. ACM Press (2013), 65-69.

12. Handa, C. Visual Rhetoric in a Digital World. Bedford/St. Martin Press, 2004.

13. Hill, C.A., \& Helmers, M. (Eds.) Defining Visual Rhetorics. Lawrence Erlbaum Associates, 2004.

14. Hullman, J., \& Diakopoulos, N. Visualization Rhetoric: Framing Effects in Narrative Visualization. T. on Visualization and Computer Graphics 7, 12 (2011) 22312240

15. Kannabiran, G., \& Graves Petersen, M. Politics at the interface: A Foucauldian power analysis. In Proc. NordiCHI 2010. ACM Press (2010), 695-698.

16. Nassri, A. Gaza Everywhere (2014, August 8). URL: http://ahmadnassri.github.io/gaza-everywhere/

17. Nelson, H.G., \& Stolerman, E. The Design Way. MIT Press, 2012

18. Price, J. A Rhetoric of Objects. SIGDOC '01. ACM Press (2001), 147-151.

19. Redström, J. Persuasive Design: Fringes and Foundations. W. IJsselsteijn et al. (Eds.) PERSUASIVE 2006, LNCS 3962 (2006), 112-122. Springer.

20. Rosinki, P., \& Squire, M. Strange Bedfellows: HumanComputer Interaction, Interface Design and Composition Pedagogy. Computers and Composition 26, 3 (2009), 149-163. Elsevier.

21. Schön, D.A. The Reflective Practitioner. How Professionals Think In Action. Basic Books, 1984.

22. Sosa-Tzec, O., \& Siegel, M.A. Rhetorical Evaluation of User Interfaces. NordiCHI '14. ACM Press (2014), 175 178.

23. Torning, K., \& Oinas-Kukkonen, H. Persuasive System Design: State of the Art and Future Directions. Persuasive '09, ACM Press (2009).

24. Kord. Y., IJsselsteijn, W., Midden, C., Eggen B., Fogg, B.J. (Eds.) Persuasive Technology. $2^{\text {nd }}$ International Conference on Persuasive Technology, PERSUASIVE 2007. Revised Selected Papers. Springer (2007). 